\title{
A QUALITATIVE STUDY USING A SYSTEMIC PERSPECTIVE EXPLORING THE REMEDIATION OF ABUSIVE INTERACTIONS IN INTIMATE HETEROSEXUAL COUPLES.
}

$\underline{\text { Authors }}$

Dr Elizabeth Bonham, Consultant Clinical Psychologist

Doctorate in Clinical Psychology, City University, UK

MSc Psychopathology, Leicester University, UK

MSc Clinical Psychology, Surrey University, UK

lizziebonham@yahoo.co.uk

Professor Arlene Louise Vetere, $\mathrm{PhD}$

Deputy Director PsychD In Clinical Psychology, University of Surrey,

< A.Vetere@ @urrey.ac.uk.> 


\begin{abstract}
Very little attention has been paid to both partners beliefs about why violence in their previously abusive relationship has stopped or significantly reduced despite well documented details in the research literature outlining the characteristics of both victims and perpetrators. This study aimed to provide some understanding of how each partner believed that the violence has ended. However their answers often were not definitive instead they uncovered the complexities in their relationship and their struggle to overcome the uncertainty they have to achieve and maintain successful remediation.
\end{abstract}

The paper is based upon a qualitative Interpretative Phenomenological Analysis (IPA) study that explored the nature of the relationship between six heterosexual couples before and after a therapeutic intervention for the men perpetrators which followed the Duluth Model. The study included how they both understood the violence and how they maintained non violence in their relationship. The men were notably still in the process of reprocessing their understanding of why they were violent and they needed to further understand their reactions to maintain their non violence. The IPA themes provided some understanding of how the participants thought they had a better understanding of the factors that had maintained their relationship since the termination of the intervention. The themes, generated from the interviews provided by the perpetrators and their victims, are explored and some explanations for the successful continuation of their relationship following treatment are suggested. Implications for widening the treatment options for men perpetrators are suggested in addition to providing treatment options for couples who wish to remain within their relationships and need help to identify unhelpful and dangerous patterns of interaction.

Keywords: Partner Abuse, Systemic Approach, Social Constructionism, Attachment. 


\section{INTRODUCTION}

The focus of the study is on the narratives of couples, the victims and the perpetrators of the violence. There was a willingness amongst participants to try and understand the dynamics within their relationship and to see the links to the violence, why it has stopped and their decision to remain together.

Research in the field of domestic violence has largely been concerned with the genesis and maintenance of violent behaviour encountered in intimate adult relationships. Evaluative studies concerning treatment programmes designed to prevent domestic violence have indicated that some couples wish to remain in their relationships and in some of these cases the violence has stopped or been substantially reduced following treatment interventions (Stith, Rosen and McCollum, 2003). Often the focus of domestic violence programmes, usually where men are the perpetrators, has been to help men manage their anger and aggression and accept responsibility for the violence they have inflicted. Because it is generally accepted that many of the reasons men or women perpetrate violence is rooted in their early experiences within their family, it is suggested that to look more systemically at the relationship dynamics between the perpetrator and the victim could provide a better understanding of why victims remain with or return to their violent partners (Stith, McCollum, Rosen, and Locke, 2002). Too often violence can reoccur between couples following treatment (Klein, Andrew, Tobin, Terri, 2008) where success of an intervention is defined by cessation of men's physical abuse against their intimate partner (Scott, 2004).

This research focused on couples' personal perspectives of why the violence occurred and was maintained in their relationship. This was essential for change within their relationship 
to occur. An interview study was undertaken and attempted to achieve a more systemic understanding by exploring the nature of the violent behaviour that occurred between couples, their reciprocal relationship, the intergenerational legacies of this violence and the psychosocial context within which the violence occurs. This approach mirrors an essentially ecological model initially proposed by Bronfenbrenner (1977) to identify different contextual levels of meaning and action to explain human behaviour. The research framework was systemic and combined ideas from social constructionism and attachment theory to provide a theoretical underpinning.

The theoretical approaches outlined below provide a backdrop to the themes generated from the participants interviews.

\section{ATTACHMENT PROCESSES}

Interest in Attachment Theory has currently been revived in relation to men who are violent. Bowlby would argue that identities of individuals are defined by the quality of their early attachment relationships. Dutton's (1998) research suggested that relationships with cold, rejecting and abusive fathers who humiliate their sons and with emotionally unavailable mothers, produces in men/boys a sense of shame about themselves. This results in them developing a poor sense of self and by then identifying with their abusive father they are able to feel better about themselves. These insecure attachments can lead to chronic difficulties with intimate relationships in adult life which often occur between perpetrators of violence and their intimate partners. 
It was with these ideas in mind that it became important to the authors to carry out a study involving both victims and perpetrators in heterosexual relationships, to explore the nature of their reciprocal relationships, to consider what they thought might account for the violence stopping, the impact this has had on their lives and how this had currently affected their relationship.

\section{INFLUENCES FROM SOCIAL CONSTRUCTIONISM}

Foucault (1980) argued that powerful societal discourses can determine what is appropriate for individuals to think and discuss. Feminist thinking has maintained that dominant patriarchal discourses have served to construct and legitimise patterns of violence against women (Alcott and Gray, 1993). Therefore violence in this model can be seen as a strategy of intimidation in the service of male domination (Goldner, 1992). Social constructionism emphasises the centrality of power in those relationships within which we develop over time. It is argued we are immersed in a social world of meaning and interaction with others which incorporates society's values and beliefs about men and women. These are transmitted through family myths and beliefs as well as potent messages filtered by the media and other cultural influences for example, religion and status.

\section{THE STUDY}

The study aimed to explore both men's and women's understandings of the successful remediation of the violence in their relationship. In particular, what factors were perceived to have led to the cessation of violence and what aspects of their relationship kept them together 
and continued to do so, despite concerns about the possibility of future recurrence of violent behaviour.

Men participants who participated in the intervention were recruited largely from a voluntary treatment group for anger management, although one was recruited from a statutory organisation, none of the men had been violent since treatment ended. Women participants were invited to join their men partners in the study and were assured that they would be interviewed separately from their men partners giving independent confirmation that the violence had indeed ceased.

\section{INTERVIEW SCHEDULE}

Six British couples were interviewed as separate individuals about their experiences of coping with domestic violence. The semi-structured interview covered the violence that occurred within their relationships, their understanding of why it had stopped and the effect that this now had for each of them on their relationship. Due to the nature of the topic, a sensitive method of interviewing was used which was based upon an interactional style derived from counselling (Coyle, 1988). The interviews lasted between one and two hours. All were audio-recorded and transcribed verbatim for subsequent qualitative analysis.

\section{RESULTS}

The data were analyzed using IPA (Smith, Jarman and Osborn, 1999) which provides a systematic method of analysing qualitative data to explore participants' experiences and cognitions and the meaning they attribute to these. There is recognition, however, that the 
outcome of any qualitative analysis represents an interaction between participants' accounts and the researcher's interpretative framework. Analysis is undertaken with the assumption that meaningful interpretations can be made about what a person is thinking from their verbal reports (Smith et al, 1999), therefore it is necessary to outline the analytic procedure systematically. Repeated reading of the transcripts resulted in notes being made on each transcript regarding key phrases and processes. These notes included summaries of content, connections between different aspects of the transcript and initial interpretations within each transcript. These notes were clustered to produce initial themes. Care was taken to ensure that these themes were consistent with and could be confirmed from the data. This process was repeated for each transcript and any recurrent patterns across all the initial themes were identified producing a final set of superordinate themes. The links between these themes and the data were again checked. Themes were then ordered in such a way as to produce a logical and coherent research narrative. Inevitably each analysis involved a level of subjectivity because it was shaped by the researcher's interpretative framework. The validity of the analysis was, however, supported by an independent auditor.

Examples of key superordinate themes from the research will be illustrated using transcripts of two of the couples. These couples realised that to change deep seated patterns of violent behaviour they needed to understand what created this violent reaction. Their thoughts and feelings are outlined in the following IPA themes. 
Table 1 Master, Superordinate and Emergent Themes for Women and Men

\begin{tabular}{|c|c|c|c|}
\hline & Master Themes & Superordinate Themes & Emergent Themes \\
\hline \multirow[t]{4}{*}{1} & Attachment & - Negative early experience & \# Relationship with parent \\
\hline & & - Repeated violent relationships & \\
\hline & & - Chaotic lifestyle & \\
\hline & & - Insecurity & \\
\hline \multirow[t]{5}{*}{2} & $\begin{array}{l}\text { Meaning of } \\
\text { relationships }\end{array}$ & - Relationship dynamics & \\
\hline & & - Idealisation & \\
\hline & & - $\quad$ Family influences & \# Compatibility \\
\hline & & - Communication & \\
\hline & & - $\quad$ Trust & \# Intimacy \\
\hline 3 & $\begin{array}{l}\text { Meaning of } \\
\text { violence }\end{array}$ & - Familiarity with violence & \\
\hline & & - Impact of violence & $\begin{array}{l}\text { \# Power } \\
\text { \# Vigilance } \\
\text { \# Recurring images } \\
\text { \# Dangerousness } \\
\text { \# Sensitive to violence }\end{array}$ \\
\hline & & - Not making sense of violence & \\
\hline & & - Responsibility & \\
\hline & & - Acceptance & \\
\hline & & - $\quad$ Denial & \\
\hline 4 & $\begin{array}{l}\text { Therapeutic } \\
\text { support }\end{array}$ & - Impact of an intervention & \\
\hline & & - $\quad$ Need for help & \\
\hline
\end{tabular}

\section{KEY IPA THEMES}

\section{Violence and Attachment}

Contrary to everyday expectations children who have been abused often form strong attachment bonds with their abusive primary caregivers which are characterized by closeness and anger (Dutton, 1998). Such anger can often remain dormant until another intimate relationship is formed when often they fail to understand each other's and their own reactions which can stem from early attachments. Often people do form relationships with people from a similar attachment background. The following examples from one couple demonstrate 
this*, it illustrates their struggle to understand the violence within their relationship in order to bring about change. Moreover, appreciating the link between violence and attachment provided the couples with a better understanding of the value of their relationship.

Sean:- $\quad$ 'I hurt myself, punched and kicked things, what I'm doing is almost childlike I mean a child's voice 'I'm angry' ... when I was younger I cut myself, I couldn't handle my rage ... what I am saying is 'you hurt' of course she doesn't know she (partner) is hurting me unless I tell her.'

Emma:- 'We looked at our past it helped us link (our) abusive relationship. It helped us link the past with what we were creating. Did we really want to go on creating that... and we didn't - and I think that helped.'

Sean:- $\quad$ 'I think that our childhood times fit into a lot with long term relationships ... I was nasty and yet I could be very caring and loving ... I think that appeals to my wife.'

In this example the participants are beginning to understand their own feelings which can spiral towards violence.

Emma:- 'I also realise that apart from that violence I had my own side, something about the excitement of it ... the drama of it, it was so familiar with the drama from my childhood.'

*Emma and Sean; Jessica and Sebastian were couples (names have been changed). 
Emma:- $\quad$ 'It was so familiar to me in the past, the whole thing, drama and the nice bit and then the spiral and the familiarity, maybe it was just like it would be boring ... it was only when I was pregnant I could make the connection really. I didn't want to inflict that on the baby!'

Sean:- 'My anger [is that] Emma shuts down ... she is empty, there is nothing, somehow I sense that I get so angry, I am not discussing it with her, I'm not telling her how I feel, I am pointing a finger at her, she is the one who is making it worse.'

Feelings of uncertainty and lack of trust were reflected in the next example from another couple linking the participants' insecure attachment style and his violence to his partner. There appears to be an understanding of the process involved in the interaction but an inability to fully internalise the feelings to be able to change the behaviour.

Sebastian:- 'I am still aware that it could all be taken away from me. I could still mess up her and myself if I am violent again ... there are times when I snap at Jessica ... She will retreat and won't want to be close and there are times when she will want affection and I can't give it to her because I'm too scared, so there is this constant to-ing and fro-ing and we never meet in the middle.'

Jessica:- 'I think being abused (early experience), you attribute a lot of the success of your marriage to how much sex you are having. It gets confused with love.' 
Emma:- 'There is an avoidance of not dealing with it ... everything is o.k. ... so I don't have to deal with it but it is still there ... it is not good for us ... there is still a lot of work to do.'

\section{Meaning of Relationships}

Relationships had different meanings for these men and women and their discourses at times reflected a familiar and recurring pattern of behaviour that occurred throughout previous generations. A belief they were retracing old family pathways; how those relationships are acted out and the effect they have on the other person. Two participants raised the issue of control and the meaning they felt was relevant to their own relationship:-

Sean:- $\quad$ 'I can be violent, but also loving ... it's almost like scales ... I think that appeals to someone like my wife and my mother ... Emma saw that maybe I can change but there is a pattern that goes on, there is a dynamic between us which is very similar to (that of) my parents, very similar to her own family.'

Sean:- $\quad$ 'I want control, I wanted her to be a certain way ... we felt we were negotiating but we weren't really!'

Jessica:- 'I perhaps emotionally control Sebastian ... I'm not sure ... I think for me he probably feels really pent up and gets frustrated because he is not sure how I am doing it and I'm not sure how to do something about it.'

One participant started noticing changes in their own relationships following the intervention. 
Sean:- 'I am moved when someone is trying to identify their feelings ... their experience and they can't find the words in twenty minutes - they really try hard to identify what is going on because they didn't know.'

Sean:- $\quad$ 'I think then (in the group) it started to resonate with me ... I would share and get quite emotional about things.

\section{Meaning of Violence}

Both men and women struggled to make sense of the man's violence. Men became very confused about their violent behaviour and could make no sense of it. Although they agreed it was unacceptable they found they were often unable to control their violence. The intervention provided a greater awareness of the consequences of their violent actions but not the intensity of their feelings.

Sean:- $\quad$ 'I didn't know what is going on, what is going wrong, why am I doing this.'

Sebastian:- 'I would be a lot happier to first be calm and relaxed, so maybe that is why people don't (become violent). Also it is not acceptable I know but it doesn't seem to make any bloody difference to my behaviour.'

Emma:- 'I couldn't understand what was happening that was part of it, not understanding why (he had) these huge mood swings.' 
Sebastian:- 'I'm a lot more sensitive to violence around me. I listen to people talk, I'm not sure what the connections are in the violence ending but I'm a lot more aware of personal habits, behaviour and trying to keep tabs on everything.'

Jessica:- 'He called me a fucking slag ... names that have no relevance to me whatsoever. I can understand him calling me a bitch but a slag is something I'm most definitely not.'

Despite often feeling confused about their partners' violence the women had some interesting insights into the causes of their partners' violence. They were able to reflect upon their own past and make connections about the violence that was occurring between them, but were not always able to behave differently in order to avoid the violence.

Emma:- $\quad$ 'There are connections between them ... it's all familiar to me, chaotic lifestyle all that chaos. You don't know whether you stay with him, your job is up in the air ... so I can imagine what it was like for my mum.'

Jessica:- 'Although he had a temper before me being someone like me has not helped because I have created a scenario which is very similar to the one I had when I was growing up frightened of my parents but loving my parents.'

\section{DISCUSSION}

Participants understanding of why the violence has stopped

In the group of people involved in this study the initial prompt for the violence to stop came mainly from the women who had insisted that the men fought help for their violent 
behaviour. This was further strengthened by the therapeutic intervention in particular in respect of the seriousness of the violence. However, the results illustrated that both men and women reflected further on their own previous experiences of violence and the subsequent violence in their relationship to try and understand any connections between them. This was outlined in the key themes. In an attempt to understand their violent behaviour the men struggled with the intensity of feelings that provoked their violence despite finding their intervention programme a helpful first step. Although some had started to become selfreflective about the impact of their violent behaviour, understanding the root of their violence remained elusive. They felt it was imperative to understand more fully in order to prevent violence erupting again.

For some the universal existence of violence in society was also awakened and they begun to recognise potential violence within their environments in the way people talked. In some cases it appeared to facilitate reprocessing which had an effect on their own violent relationship. This would highlight that violence is not solely an internal event and other systemic considerations have to be thought of when considering prevention.

Sebastian:- $\quad$ 'I'm a lot more sensitive to violence around me. I listen to people talk, I'm not sure what the connections are in the violence ending but I'm a lot more aware of personal habits, behaviour and trying to keep tabs on everything.'

In some cases feelings of abandonment were replaced by feelings of belonging. This highlighted the paradox between the need for a secure base and the familiarity of the violence. Attachment processes could be seen as a process to consider. It seemed that 
participants were beginning to appreciate this as a factor. This is outlined in the examples below.

Sean:- $\quad$ 'She is changing, he (their baby) is more important. I am more important as a family and so she has been through this process.'

Emma:- 'It was so familiar to me in the past, the whole thing, drama and the nice bit and then the spiral and the familiarity, maybe it was just like it would be boring ... it was only when I was pregnant I could make the connection really. I didn't want to inflict that on the baby!'

Although some of the men realised they had experienced unsatisfactory nurturing from their parents, their inability to 'mentalize' (Fonagy and Target, 1999a) effectively meant they were unable to appreciate fully the inappropriateness of the strength of their reaction. It was because of this that many of the men wanted to explore their feelings further.

Sebastian:- 'I wanted her dead ... the look on her face snapped me out of it ... you are going to kill her if you carry on.'

Sean:- 'I am moved when someone is trying to identify their feelings ... their experience and they can't find the words in twenty minutes - they really try hard to identify what is going on because they didn't know.'

Emma:- 'There is an avoidance of not dealing with it ... everything is o.k. ... so I don't have to deal with it but it is still there ... it is not good for us ... there is still a lot of work to do.' 
Participants within this study were beginning to reflect the issues emerging from key themes in the study. These needed to be addressed if non-violence in their relationship were to be maintained. Follow up studies would benefit from further exploration of these themes to establish processes that can be incorporated within therapy programmes.

\section{IMPLICATIONS FOR CLINICAL PRACTICE}

It is essential to be aware of the importance of contextual issues when considering the remediation of violent behaviour. Violence can evoke a number of strong feelings such as disgust, shame and horror which are often fuelled by a particular moral position (Hannah and McAdam, 1991). This can create ambiguities which hinder our understanding of why violence occurs which adds confusion to perpetrators and to the sense perpetrators make of their own violence. When a story is told, connections are made between events and ideas depending on who is talking to whom and the context in which it is said. Hannah et al (1991) would therefore argue that through socially constructed conversations, patterns emerge forming socially negotiated meaning which can mould our beliefs. These are constantly evolving through conversation, action and reflection upon experience and as a result these beliefs can alter. Awareness of these contextual links is one way of helping us and perpetrators of violence understand the way in which individuals can interpret the same events differently.

The results demonstrated a limited awareness of the factors that maintained their relationship, for example, an appreciation of the reciprocal relationship that operated between them but it led them to seek help to further explore their feelings. In general the women did not 
acknowledge their own needs and wishes and the men remained confused about why they were so violent and the function it may have within their relationship. This resulted in the women not fully understanding their partners' violence and men not fully understanding their need for control over their partner and their apparent powerlessness in their ability to understand or achieve it.

However, there were a number of factors which affected the development of violent behaviour, within intimate relationships. The impact of early trauma which participants described in the section on violence and attachment needs exploring when managing violent behaviour. A re-experiencing of physical sensations of past trauma can occur without the person's awareness or ability to analyse these feelings. Intense emotions are overwhelming and they are unable to modulate or regulate them. Brewin (1996) argues that such trauma memories, called Situationally Accessed Memories (SAM) do not require conscious appraisal, have no temporal context and therefore are experienced in the here and now. It is important to help perpetrators of violence understand these sensations. Also, partners need help to understand the emotional difficulties their partner's experience which are often extreme and between them find ways they can behave differently.

Furthermore Crittenden (1999) argues that intimate attachment figures can trigger a memory of an original traumatic attachment. This can result in difficulties with intimacy where rejection is often misinterpreted. Neglectful absent fathers can undermine particularly male infants'/ young boys' ability to modulate aggression (Herzog, 1982). As a result, chronically rejected infants can experience strong violent impulses. Therefore, alternative explanations need to be found by them to help contain any unhelpful thoughts and intense feelings they might have. Furthermore inter-generational replication of traumatic experiences of violent 
behaviour are a result of witnessing violent behaviour in families, where violence can often be normalised. Therefore the context is important and needs to be accounted for when considering therapeutic interventions.

Any well designed therapeutic interventions have some positive outcomes but often issues contributing to the problems outlined are not addressed, for example, why am I violent now? However, childhood resilience must not be forgotten. Men need to make sense of the strong puzzling emotions they feel and be able to reprocess them effectively. These emotions are seldom dealt with in many group anger management programmes for perpetrators. Often the decision to enter therapeutic work is not based on a clients' readiness for change (Di Clemente and Prochaska, 1984) and as a result the intervention may fail. This can leave participants feeling disappointed and risks introducing the possibility of greater resistance to change. This suggests that there is an argument for a more multi-treatment approach following good initial assessments. It is also essential, that where therapists from different agencies are involved there is initial agreement on issues such as overall policy, risk taking and safety (Vetere and Cooper, 2003). Overall a more eclectic, theoretically integrative, less dogmatically oriented pattern of intervention would appear to have much to offer both the clients and the therapist. 


\section{Bibliography}

Alcott, L., and Gray, L. (1993). Survivor discourse: Transgression or recuperation signs18121. 260-290.

Bowlby, J. (1984). Violence in the family as a disorder of attachment and care giving systems. American Journal of Psychoanalysis, 44(1), 9-27.

Brewin, C.R., Dalgleish, T. And Joseph, S. (1996). A dual representation theory of post traumatic stress disorder. Psychological review. 103(4), 670-680.

Bronfenbrenner, V. (1977). Toward an experimental ecology of human development. American Psychologist. S13-S31.

Coyle, A., Good, A. and Wright, C. (1994). The counselling interview as research method. Paper presented at the Annual Conference of the British Psychological Society, Brighton, 2427 March.

Crittenden, P.M. (1999). Trust, Error, Omission, Distortion, and Deception: The application of attachment theory to the assessment and treatment of psychological disorder in S.M. Clancy, Dollinger and L.F. Dialla Eds. Assessment and intervention issues across the span. Lawrence Erlbaum Associates, Publisher London. 
Di Clemente, C.C., and Prochaslza, J.B., (1984). 'Processes and stages of change: coping and competence in smoking behaviour change'. In S. Shiffman and T.Wills (Eds), Coping and substance abuse. New York: Academic press.

Dutton, D.G., (1998). The abusive personality in intimate relationships. Guildford press. New York, London.

Fonagy, P., and Target, M.(1999a). Towards understanding violence. The use of the body and the body and the role of the father. In R.J. Perelberg (Ed). Psychoanalytic understanding of violence and suicide. London: Routledge.

Foncault, M. (1980). Power/knowledge selected interviews and other writings 1972-77 (Ed and trans. C. Gordan). Brighton: Harvestor Press.

Goldner, V. (1992). Love and violence; gender paradoxes in volatile relationships. Family process, 29: 343-64.

Hannah, C., and McAdam, E., (1991). Violence part 1: Reflections on our work with violence. Human systems: The journal of systemic consultation and management. Vol 2 201216.

Herzog, J.M. (1982). 'On father hunger: the father's role in the modulations of aggressive drive and fantasy; in S.W. Catlis., A.R. Gurwitt, and J.M. Ros (Eds). Father and child. Boston: Lille. Brown pp 163-174. 
Klein, A.R., Tobin, T. (2008). A longitudinal study of arrested batters, 1995-2005: Career criminals. Violence Against Women. Vol. 14(2), pp136-157.

Scott, K.L. (2004). Predictors of change among Male Batterers: Applications of theories and review of empirical findings. Trauma, Violence and Abuse. Vol. 5(3), pp260-284.

Smith, J.A., Jarman, M., and Osborn, M. (1999). Ed. M. Murray \& K. Chamberlain: Qualitative Health Psychology. Theories and Methods. Sage.

Stith, S.M., McCollum, E.E., and Rosen, K.H., and Locke, L.D. (2002). Multi couple group treatment for domestic violence in F. Kaslow (Ed). Comprehensive textbook of psychotherapy. (Vol 4). New York: John Willey and Sons.

Stith, S.M., Rosen, K,H., and McCollum, E.E., (2003). Effectiveness of couples treatment for spouse. Journal of Marital and Family Therapy. (Vol 29) No 3407046.

Vetere, A., and Cooper, J. (2003). Setting up a domestic violence service. Child and adolescent Mental Health, 8, 61-67. 